\title{
RIPARIAN ZONES INCREASE REGIONAL SPECIES RICHNESS BY HARBORING DIFFERENT, NOT MORE, SPECIES
}

\author{
John L. Sabo, ${ }^{1}$ Ryan Sponseller, Mark Dixon, Kris Gade, Tamara Harms, Jim Heffernan, \\ Andrea Jani, Gabrielle Katz, ${ }^{2}$ Candan Soykan, James Watts, and Jill Welter \\ Faculty of Ecology, Evolution and Environmental Science, School of Life Sciences, Arizona State University, \\ P.O. Box 874501, Tempe, Arizona 85287-4501 USA
}

\begin{abstract}
Riparian zones are habitats of critical conservation concern worldwide, as they are known to filter agricultural contaminants, buffer landscapes against erosion, and provide habitat for high numbers of species. Here we test the generality of the notion that riparian habitats harbor more species than adjacent upland habitats. Using previously published data collected from seven continents and including taxa ranging from Antarctic soil invertebrates to tropical rain forest lianas and primates, we show that riparian habitats do not harbor higher numbers of species, but rather support significantly different species pools altogether. In this way, riparian habitats increase regional $(\gamma-)$ richness across the globe by $>50 \%$, on average. Thus conservation planners can easily increase the number of species protected in a regional portfolio by simply including a river within terrestrial biodiversity reserves. Our analysis also suggests numerous possible improvements for future studies of species richness gradients across riparian and upland habitats. First, $<15 \%$ of the studies in our analysis included estimates of more than one taxonomic group of interest. Second, within a given taxonomic group, studies employed variable methodologies and sampling areas in pursuit of richness and turnover estimates. Future analyses of species richness patterns in watersheds should aim to include a more comprehensive suite of taxonomic groups and should measure richness at multiple spatial scales.
\end{abstract}

Key words: conservation planning; regional diversity; riparian zone; river; similarity; species diversity; species richness; turnover; upland; watershed reserves.

\section{INTRODUCTION}

Conservation portfolios are typically drafted with the goal of protecting target habitat types that support high species richness, diversity, or endemism at an ecoregional scale (Groves et al. 2000). Relevant to this effort is the idea that rivers create strong gradients in species richness along riparian-upland transitions in vegetation. Specifically, riparian habitats are often cited as harboring higher numbers of species than adjacent upland habitats within the same geographic location (Naiman et al. 1993, NRC 2002). This pattern has been observed in some systems (McIntyre 2000, Woinarski et al. 2000, Catterall et al. 2001, Brown and Peet 2003), but not in others (McComb et al. 1993, Hughes and Cass 1997, Treonis et al. 1999, Catterall et al. 2001, Pearson and Manuwal 2001). In some systems, in fact, the opposite gradient (higher upland diversity) has stronger support (McGarigal and McComb 1992, Kirkman et al. 1998, Burnham 2002, Schade et al. 2003). Curiously, despite the large number of primary studies evaluating differences in richness between riparian and

Manuscript received 15 April 2004; revised 21 June 2004; accepted 24 June 2004. Corresponding Editor: T. J. Stohlgren.

${ }^{1}$ E-mail: John.L.Sabo@asu.edu

${ }^{2}$ Present address: Department of Geography and Planning, Appalachian State University, 426 Rankin Science Building, Boone, North Carolina 28608 USA. adjacent upland habitats, the hypothesis that riparian habitats have higher richness has not been evaluated more generally across larger geographic scales or major taxonomic groups.

In this paper we address four general questions about riparian-upland gradients in species richness: (1) Does average richness (reflecting $\alpha$-diversity) differ between riparian and upland habitats across all replicated studies examining this question? (2) Does cumulative richness differ between riparian and upland habitats (reflecting differences in the relative turnover of species among plots, or $\beta$-diversity, within each habitat)? (3) Is turnover in species richness ( $\beta$-diversity) significant between riparian and upland habitats, reflecting greater regional richness ( $\gamma$-diversity) of larger landscape elements that include riparian zones? (4) Do observed patterns of relative species richness (reflecting $\alpha-, \beta-$, or $\gamma$-diversity) in riparian and upland habitats depend on regional climate or the taxonomic group of interest?

\section{Methods}

\section{Literature search}

To assess the generality of gradients in species richness between riparian and upland habitats, we searched for papers reporting estimates of species richness in riparian and upland habitats published between the years 1955 and 2003 using the Web of Knowledge 
(Thomson ISI, New York, New York, USA). ${ }^{3}$ Here, we defined "riparian" broadly as any terrestrial habitat adjacent to a river, lake, or wetland habitat as per the National Research Council (NRC 2002). To find appropriate articles, we used the search terms riparian, upland, species, richness, divers $\$$ and biodivers $\$$. This search initially produced a library of $>6000$ abstracts. We narrowed this initial library to $>2000$ articles by discarding articles from journals or titles from unrelated fields of study (e.g., genetics, geology). We further narrowed this library to $\sim 150$ articles based on information provided in abstracts in our ISI database suggesting that estimates of diversity in riparian and upland habitats might be found in these papers. From this final library, we found papers containing three types of data: estimates of mean richness in riparian and upland habitats (with associated sample sizes and variance estimates), estimates of richness pooled across replicate sites in riparian and upland habitats, and estimates of turnover in richness between riparian and upland sites. Many papers provided all three types of data.

From this initial library we identified 47 papers (Appendix A) that explicitly enumerated species richness in both riparian and upland habitats or turnover in species pools between these two habitats (Appendix A). Representative studies were conducted on all seven continents, examining patterns of richness in taxa as diverse as desert soil fungi and tropical rain forest primates (Appendix A). Distances separating riparian and upland habitats varied widely (all values reported as mean $\pm 1 \mathrm{sE}$ unless otherwise noted; $663.86 \pm 212.47$ $\mathrm{m})$, probably reflecting the effect of regional climate on soil moisture and, thus, the relative dependence of riparian flora on surface water. Of these 47 papers, only 21 were replicated (multiple plots sampled in riparian and upland habitats) and reported average richness estimates, sample size, and an associated variance estimate for richness in both habitats. Of these 21 papers, many reported richness estimates for multiple taxonomic groups. In these cases, we used each taxonomic group as an independent primary study in our analysis, based on the authors' best judgment to split these groups. Most papers reported data describing more than one group of taxa, providing a larger number of primary records from which to estimate effect sizes $(N=37)$. Within a particular taxonomic group (e.g., woody plants, birds, soil fungi), we consistently pooled native and non-native species in an attempt to make richness estimates more consistent between studies that reported separate estimates of natives and non-natives and studies that did not differentiate between these two groups.

Meta-analysis: gradients in mean richness between riparian and upland habitats

Using our final data set, we estimated the effect size for each taxonomic group in each (replicated) study as follows:

\footnotetext{
${ }^{3}\langle$ http://www.thomsonisi.com $\rangle$
}

$$
d_{i}=\frac{\bar{X}_{\mathrm{r}}-\bar{X}_{\mathrm{u}}}{s_{\mathrm{r}+\mathrm{u}}}
$$

where, $d_{i}$ is the unweighted effect size of the $i$ th record, $\overline{\mathrm{X}}_{\mathrm{r}}$ and $\overline{\mathrm{X}}_{\mathrm{u}}$ are average richness estimates in riparian and upland habitats, respectively, and $s_{\mathrm{r}+\mathrm{u}}$ is the pooled standard deviation of mean estimates from the two habitats in each study. The average weighted effect size, and thus difference in richness between riparian and upland habitats, was then calculated using a mixedeffects model (Gurevitch and Hedges 2002). Estimates of the average weighted effect size $\left(d_{i+}\right)$ and associated confidence intervals were then used to test two null hypotheses: (1) that richness does not differ between riparian and upland habitats (i.e., $H_{0}: d_{i+}=0$ ), and (2) that this result is consistent across all 37 records used in our analysis (i.e., $H_{0}$ : no heterogeneity in $d_{i}$ among records). In all analyses and figures, positive effect sizes indicate higher riparian richness, negative values indicate lower riparian richness, and values near zero indicate no difference between richness in riparian and upland habitats for a particular study.

We then explored the effects of climate and taxonomic grouping on mean effect size, $d_{i+}$, and heterogeneity in $d_{i+}$ by incorporating these factors into the data structure of our meta-analysis (Gurevitch and Hedges 2002). Studies were classified as plant $(N=$ $22)$ or animal $(N=15)$ and dry $(N=17)$ or wet $(N$ $=30$ ) hydrographic regions for each analysis, respectively. We used average annual rainfall estimates to categorize studies into two a priori climate categories: dry (arid and semiarid ecosystems, rainfall $<70 \mathrm{~cm}$ ) and wet (mesic and wet ecosystems, rainfall $>70 \mathrm{~cm}$ ). All studies included in the dry category were from regions recording $<60 \mathrm{~cm}$ of rainfall annually (35 \pm $5.53 \mathrm{~cm}$ ). A majority of these studies recorded $<40 \mathrm{~cm}$ (range $10-60 \mathrm{~cm}$ ). Studies included in the wet category were from regions recording substantially more annual rainfall $(135.23 \pm 17.56 \mathrm{~cm}$; range, $77-286 \mathrm{~cm})$. Of these studies, a majority recorded $\geq 100 \mathrm{~cm}$ of average annual rainfall. Our dry category includes study sites in Köppen's Dry (B), Mediterranean (Csa), and Polar (E) climates (Trewartha 1937), whereas our wet category includes study sites in primarily tropical (A), mild mid-latitude (C, other than Mediterranean), and cold (D) climates.

The effects of climate (dry vs. wet) and taxonomic grouping (animal vs. plant) on heterogeneity in $d_{i+}$ were tested with two separate mixed-effects models (Gurevitch and Hedges 2002). We could not combine these two factors in a single factorial mixed-effect model due to large discrepancies in cell sizes. Finally, within each category of study (dry, wet, animal, and plant), we evaluated the null hypothesis that mean effect size was not different from zero. To correct for possible Type I error inflation associated with multiple testing, we adjusted our critical $P$ values using the Bonferroni correction. For analyses of mean effect size (five tests: all 
studies, wet, dry, animal, and plant), we used $P=0.01$ and applied $99 \%$ rather than $95 \%$ CIs, whereas for tests of heterogeneity in mean effect size (three tests: all, climate, and taxonomy), we used $P=0.0167$.

\section{Analysis of differences in cumulative richness between riparian and upland habitats}

Data used for our meta-analysis were reported as mean richness, a metric that ignores the identity of species and, thus, turnover in species composition within and between habitats. Therefore, although average richness (equivalent to a measure of $\alpha$-diversity) may not have differed, differences in cumulative richness across replicate plots in each habitat (reflecting within-habitat $\beta$-diversity) are not tested by our metaanalysis.

To assess differences in cumulative richness between riparian and upland habitats, we compiled data from 36 papers in our original library that reported cumulative totals of species observed in both habitats (53 records total, see Appendix A). Many of these records were the same studies used in our meta-analysis of gradients in average, or $\alpha$-scale richness. Using these point estimates of cumulative richness, we calculated the average percentage change in cumulative species richness between riparian and upland habitats for all 53 records combined, and when categorized by climate or kingdom. Percentage change in cumulative richness $\left(d_{\mathrm{c}}\right)$ was expressed as

$$
d_{\mathrm{c}}=\frac{X_{\mathrm{r}}-X_{\mathrm{u}}}{X_{\mathrm{u}+\mathrm{r}}}
$$

where $X_{\mathrm{r}}$ and $X_{\mathrm{u}}$ are the cumulative numbers of species in all riparian or upland plots, within a single study, and $X_{\mathrm{r}+\mathrm{u}}$ is the mean richness across both habitats in the same study. We then tested the null hypothesis that the average percentage change in cumulative richness between riparian and upland habitats was not different from zero (i.e., $H_{0}: \bar{d}_{\mathrm{c}}=0$ ). Thus, as in our meta-analysis, a significant positive value for $\bar{d}_{\mathrm{c}}$ indicates higher cumulative richness in riparian habitats. Again, we tested the same null hypothesis five times (as in the metaanalysis): once for the combined data set and once for each category of climate (2) and taxonomic grouping (2), leading to an experiment-wide Type 1 error rate of 0.226. To correct for higher experiment-wide Type 1 error, we used $99 \%$ confidence intervals to test all hypotheses based on a Bonferroni-corrected $\alpha$ level of 0.01 .

\section{Analysis of differences in turnover in species pools between riparian and upland habitats}

Finally, using a subset of the records used to estimate cumulative richness combined with other studies reporting only similarities ( $N=53$; Appendix A), we estimated similarity in cumulative species pools between riparian and upland habitats using the Jaccard index of similarity:

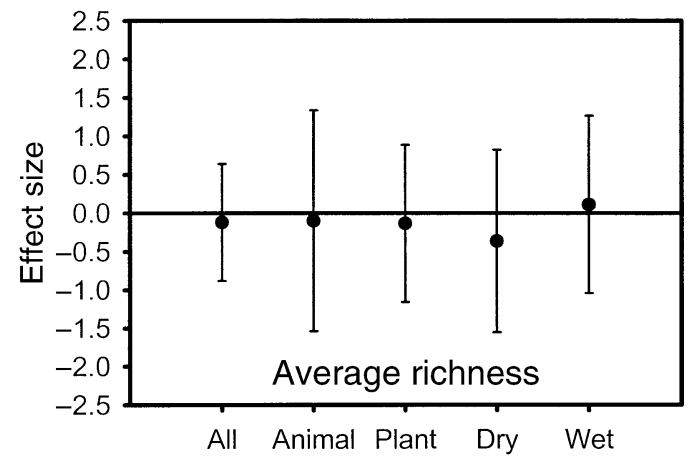

FIG. 1. Results from meta-analysis examining the difference in diversity (measured as species richness) between riparian and upland habitats. The figure shows mean weighted effect size with associated upper and lower $99 \%$ confidence interval, plotted for all records included in the analysis $(N=$ $37)$, records from dry $(N=18)$ and wet $(N=19)$ climates, and records examining animal $(N=15)$ or plant $(N=22)$ species.

$$
S_{\mathrm{J}}=\frac{c}{(a+b+c)}
$$

where $a$ is the number of unique species in riparian habitats, $b$ is the number of unique species in uplands, and $c$ is the number of species shared by both habitats for a particular study. Turnover was then estimated as $1-S_{\mathrm{J}}$, expressed as a proportion where values near one indicate high turnover in species pools between riparian and upland habitats. We tested the null hypothesis that turnover was zero (i.e., $H_{0}:\left(1-S_{\mathrm{J}}\right)=0$ ) five times and as before, used Bonferroni-corrected $P$ values and used the associated $99 \%$ confidence interval to test this null hypothesis.

\section{RESULTS}

\section{Meta-analysis: gradients in mean richness between} riparian and upland habitats

Mean effect size was low and not significantly different from zero (Fig. 1; $d_{i+}=-0.12$; upper $99 \%$ CI $=0.64$; lower $99 \% \mathrm{CI}=-0.88)$; however, heterogeneity in $d_{i+}$ was significant $\left(Q_{\mathrm{t}}=75.45\right.$, df $=36, P<$ $0.001)$. Thus, average richness was not significantly higher in riparian vs. upland habitats across the 37 data sets examined in this study. However, the range in weighted effect sizes was large (-2.49-1.79), suggesting that richness gradients were strong (in either direction) for some records but not others. Categorical analyses revealed no relationship between annual rainfall patterns or taxonomic grouping and mean effect size. Mean effect size was not significantly different between wet $(0.11 \pm 0.09)$ and dry $(-0.365 \pm 0.09)$ climates (mean $\pm 1 \mathrm{sE} ; Q_{\mathrm{B}}=\chi^{2}=0.85, \mathrm{df}=1, P>$ $0.35)$ or between animals $-0.10 \pm 0.11)$ and plants $(-0.14 \pm 0.08)\left(\right.$ mean $\pm 1 \mathrm{sE} ; Q_{\mathrm{B}}=\chi^{2}=0.0038$, df $=1, P=1)$. Finally, mean effect size was not significantly greater than zero (e.g., higher riparian diversity) 


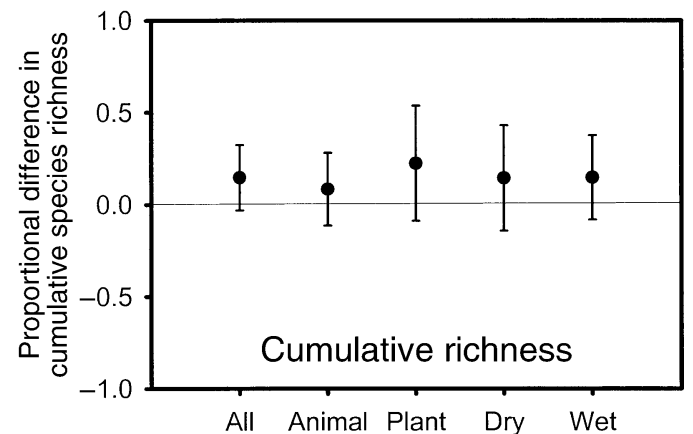

FIG. 2. Proportional change (mean with $99 \%$ confidence interval) in cumulative species richness between riparian and upland habitats. Cumulative richness was determined directly from studies $(N=53)$ reporting cumulative totals of species across multiple plots in each habitat. Positive values reflect higher cumulative richness in riparian habitats; negative values indicate higher cumulative richness in upland habitats.

for any individual rainfall or taxonomic category (Fig. 1, Appendix B). Thus, neither of these factors explains a significant source of variation described by $Q_{\mathrm{t}}$. These results were consistent for both the conservative (99\%) confidence intervals applied in our analysis and for more conventional 95\% confidence intervals (Appendix B). Thus our choice to adjust for Type I error inflation did not influence our ability to detect richness gradients between riparian and upland habitats.

\section{Analysis of differences in cumulative richness between riparian and upland habitats}

Average cumulative richness was $14 \%$ higher in riparian than upland habitats when expressed as a proportion of average richness between habitats (Fig. 2). This difference was not significant at the $\alpha=0.01$ level after correcting for multiple tests (lower 99\% CI, -0.056 ; upper $99 \%$ CI, 0.348). The percentage change in cumulative richness between riparian zones and uplands was not significantly different between dry and wet climates (Mann-Whitney $U=263, P>0.25$ ) or between plant and animal study subjects (Mann-Whitney $U=340, P>0.5)$. Finally, mean percentage change in cumulative richness was not significantly different from zero for any of the four categories of classification (see CIs in Fig. 2). As in our meta-analysis, these results were consistent for both $95 \%$ and 99\% confidence intervals (Appendix B).

\section{Analysis of turnover in species pools between riparian and upland habitats}

Average turnover in cumulative species richness between riparian and upland habitats was $\sim 50 \%$ and differed significantly from zero (Fig. 3; lower 99\% CI, $40.9 \%$ upper $99 \%$ CI, $60.4 \%$ ). Turnover was significantly higher in plant than in animal studies $(t=-7.04$, df $=49, P<0.001)$ and significantly higher in dry than in wet climates $(t=2.47$, df $=51, P=0.0169)$. Finally, turnover was significantly greater than zero for all categories of studies after controlling for experiment-wide Type I error $\left(\alpha_{\text {crit }}=0.01\right.$; Fig. 3$)$. Average turnover values (with lower and upper CIs) for animal, plant, dry, and wet categories were: $34.93 \%$ (24.93$44.91 \%)$; 70.14\% (58.97-81.31\%); 62.2\% (45.54$78.85 \%)$; and $44.72 \%$ (32.81-56.62\%), respectively). As in our analyses of mean and cumulative richness, these results were consistent for both $95 \%$ and $99 \%$ confidence intervals (Appendix B).

\section{Discussion}

High species richness is a frequently cited property of riparian zones (Gregory et al. 1991, Naiman et al. 1993, Naiman and Decamps 1997, NRC 2002). High species richness in riparian habitats could relate to a variety of factors including disturbance (PlantyTabacchi et al. 1996, Pollock et al. 1998), productivity (Pollock et al. 1998), flow-facilitated dispersal of propagules (Deferrari and Naiman 1994), and the diversity of physical conditions present at the interface between aquatic and terrestrial ecosystems (Naiman and Decamps 1997). Here we show that high species richness in riparian relative to upland habitats is not a general pattern across the globe. The difference in mean richness between riparian and upland habitats was not significantly greater than zero (Fig. 1). Similarly, differences in cumulative species richness between these two types of habitats were not significant (Fig. 2). Instead, we observed significant heterogeneity in changes in mean richness between riparian and upland habitats, and this heterogeneity could not be explained by rainfall patterns or taxonomic grouping (Fig. 1). These results suggest that future studies of species diversity in riparian settings should focus on understanding the causes of variation in species richness gradients across the riparian-upland transition.

In contrast to the lack of strong differences in the richness of species between riparian and upland habitats, we observed high $(\sim 50 \%)$ and significant turn-

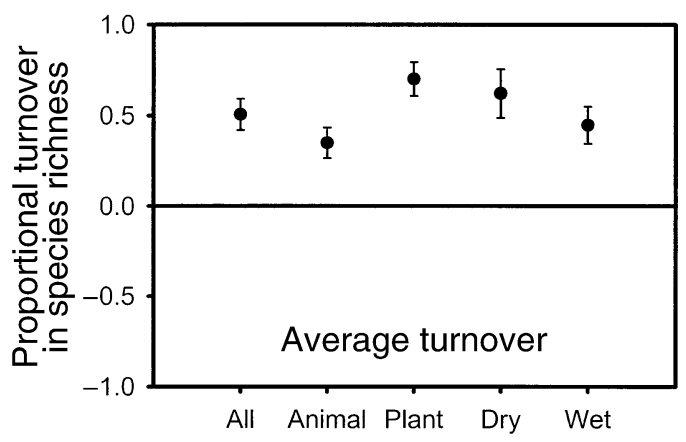

FIG. 3. Proportional turnover (mean with $99 \%$ confidence interval) between riparian and upland habitats. Turnover indices $(N=53)$ were extracted from tables or calculated from species lists provided by individual papers. Similarity between species pools in riparian and upland habitats was calculated using the Jaccard index of similarity $\left(S_{\mathrm{J}}\right)$. Turnover was then calculated as $1-S_{\mathrm{J}}$. 
over in species pools between these two habitats. This pattern was consistent globally, in dry and wet climates, and regardless of the taxonomic group being considered. Thus, although our analysis suggests that richness is not necessarily higher in riparian zones, the species pools found in riparian and upland habitats are indeed very different. Moreover, this turnover occurs in $<1-\mathrm{km}$, on average.

\section{Of lichens and primates: apples and oranges in meta-analysis}

A common criticism of meta-analysis is that the grouping of measurements made at different study sites or on different taxa using inconsistent methodologies confounds inferences about the process of interest with these other random sources of variation, the so called "apples and oranges phenomenon" (Gurevitch and Hedges 2002). In our analysis, very few studies characterized richness for more than a few closely related taxonomic groups. Only one group of studies characterized richness patterns for organisms representing more than one kingdom (Nevo 1995, Wasser et al. 1995, Nevo et al. 1996, 1999, Pavlicek et al. 1996, Grishkan et al. 2000, 2003, Finkel et al. 2001, KisPapo et al. 2001). Unfortunately, many of these records provided estimates of only cumulative richness, thus precluding them from our meta-analysis. We acknowledge here that our database consisted of richness estimates from very different systems, taxonomic groups, and study designs (see Appendix A); however, we also note that this type of comparison is exactly the point of a meta-analysis. Generality is only achieved through consistent findings across systems, study subjects, and methodologies.

These observations also illustrate a general deficiency in our current understanding of species richness patterns across the riparian-upland gradient. Very few research programs have systematically documented patterns of species richness across the riparian-upland transition for a more representative suite of taxonomic groups. More importantly, the diversity of some taxonomic groups may depend on the diversity of others. For example, plant diversity and the structure of the vegetation may determine animal richness patterns. These questions can only be answered in the context of a well-designed primary study that systematically measures richness at different taxonomic levels and represents different trophic levels (i.e., predators, herbivores, and plants). Finally, we note that richness estimates summarized by our meta-analysis and cumulative richness analysis (Figs. 1 and 2) were often derived using different methodologies (e.g., quadrats vs. line transects) and from plots of variable area. This observation suggests that future studies should also be designed to quantify richness at multiple spatial scales to allow for comparison across studies as well as to control for the effect of area on richness.

\section{Species richness, turnover, and riparian zone management}

The notion that near-river habitats support a characteristic species assemblage has enormous practical consequences for river and riparian conservation and restoration. River networks dissect landscapes and provide a natural framework for conservation planning, if these indeed influence diversity patterns. Riparian zones also have been the focus of concern in conservation efforts related to timber harvest practices and groundwater depletion (Gregory et al. 1991, Brosofske et al. 1997, Naiman et al. 2000, Glennon 2002). For example, in the Pacific Northwest (USA), "buffer strips," forested zones left along rivers in forest clearcuts, are used to reduce the effects of harvest on the abundance and richness of both terrestrial and aquatic species (Kinley and Newhouse 1997, Keith et al. 1998, Chen et al. 1999, Kelly et al. 2003, Kiffney et al. 2003). Similarly, in southwestern deserts (USA), rivers and associated forests provide critical habitat and access to surface water for a majority of North America's migratory bird species (Skagen et al. 1998), but these habitats are currently threatened by grazing and human groundwater consumption (Glennon 2002, Krueper et al. 2003).

Our results have two important consequences for river and riparian conservation. First, our results suggest that although $\alpha$-measures of diversity may not consistently differ between riparian and upland habitats, turnover in species pools ( $\beta$-diversity) between these two habitat types is consistently high and significant. High turnover in species pools between these two habitats suggests that the regional richness ( $\gamma$-diversity) encompassed by a terrestrial reserve may be maximized in conservation planning simply by including a river within the boundaries of a designated reserve. Second, turnover patterns are stronger for plants than animals and are stronger in dry than wet climates. These patterns probably reflect (1) higher mobility in animals and (2) extreme physical gradients (i.e., water, temperature) in dry climates. Mobile animals may take advantage of seasonally favorable microclimates, surface water, or other riparian conditions and resources, despite significant dependence on upland habitats. Regional climate may further dictate the degree of facultative use of riparian habitats and resources by these more mobile taxa, and upland-riparian transitions in dry regions are often characterized by major shifts in plant associations (e.g., xeric to mesic assemblages). These observations suggest even more strongly that reserves designed to protect upland habitats, per se, may fail to protect mobile taxa dependent on multiple habitats, unless some combination of riparian and upland habitats is considered together in a more comprehensive plan.

\section{ACKNOWLEDGMENTS}

We thank J. Harden, K. McCluney, R. Naiman, M. Power, T. Stohlgren, T. Rychener, D. Simmons, and two anonymous 
reviewers for helpful suggestions during the development of this analysis and comments on earlier versions of this manuscript. M. Rosenberg provided helpful guidance on the application of meta-analysis to ecological problems.

\section{Literature Cited}

Brosofske, K. D., J. Q. Chen, R. J. Naiman, and J. F. Franklin. 1997. Harvesting effects on microclimatic gradients from small streams to uplands in western Washington. Ecological Applications 7:1188-1200.

Brown, R. L., and R. K. Peet. 2003. Diversity and invasibility of southern Appalachian plant communities. Ecology 84: 32-39.

Burnham, R. J. 2002. Dominance, diversity and distribution of lianas in Yasuni, Ecuador: who is on top? Journal of Tropical Ecology 18:845-864.

Catterall, C. P., S. D. Piper, S. E. Bunn, and J. M. Arthur. 2001. Flora and fauna assemblages vary with local topography in a subtropical eucalypt forest. Austral Ecology 26: 56-69.

Chen, J. Q., S. C. Saunders, T. R. Crow, R. J. Naiman, K. D. Brosofske, G. D. Mroz, B. L. Brookshire, and J. F. Franklin. 1999. Microclimate in forest ecosystem and landscape ecology. Variations in local climate can be used to monitor and compare the effects of different management regimes. BioScience 49:288-297.

Deferrari, C. M., and R. J. Naiman. 1994. A multiscale assessment of the occurrence of exotic plants on the Olympic Peninsula, Washington. Journal of Vegetation Science 5: $247-258$

Finkel, M., O. Fragman, and E. Nevo. 2001. Biodiversity and interslope divergence of vascular plants caused by sharp microclimatic differences at "Evolution Canyon II," Lower Nahal Keziv, Upper Galilee, Israel. Israel Journal of Plant Sciences 49:285-295.

Glennon, R. J. 2002. Water follies: groundwater pumping and the fate of America's fresh waters. Island Press, Washington, D.C., USA.

Gregory, S. V., F. J. Swanson, W. A. McKee, and K. W. Cummins. 1991. An ecosystem perspective of riparian zones. Bioscience 41:540-551.

Grishkan, I., E. Nevo, S. P. Wasser, and A. Beharav. 2003. Adaptive spatiotemporal distribution of soil microfungi in 'Evolution canyon' II, Lower Nahal Keziv, western Upper Galilee, Israel. Biological Journal of the Linnean Society 78:527-539.

Grishkan, I., E. Nevo, S. P. Wasser, and T. Pavlicek. 2000. Spatiotemporal distribution of soil microfungi in "Evolution Canyon," Lower Nahal Oren, Mount Carmel, Israel. Israel Journal of Plant Sciences 48:297-308.

Groves, C. L., D. V. Valutis, B. Neely, K. Wheaton, J. Touval, and B. Runnels. 2000. Designing a geography of hope: a practitioner's handbook for ecoregional conservation planning. The Nature Conservancy. 〈http://www.conservonline. org/2000/11/b/en/GOH2-v1.pdf $\rangle$

Gurevitch, J., and L. V. Hedges. 2002. Meta-analysis: combining the results of independent experiments. Pages 347370 in S. M. Scheiner and J. Gurevitch, editors. Design and analysis of ecological experiments. Oxford University Press, Oxford, UK.

Hughes, J. W., and W. B. Cass. 1997. Pattern and process of a floodplain forest, Vermont, USA: predicted responses of vegetation to perturbation. Journal of Applied Ecology 34: 594-612.

Keith, R. M., T. C. Bjornn, W. R. Meehan, N. J. Hetrick, and M. A. Brusven. 1998. Response of juvenile salmonids to riparian and instream cover modifications in small streams flowing through second-growth forests of southeast Alaska. Transactions of the American Fisheries Society 127:889907.
Kelly, D. J., M. L. Bothwell, and D. W. Schindler. 2003. Effects of solar ultraviolet radiation on stream benthic communities: an intersite comparison. Ecology 84:2724-2740.

Kiffney, P. M., J. S. Richardson, and J. P. Bull. 2003. Responses of periphyton and insects to experimental manipulation of riparian buffer width along forest streams. Journal of Applied Ecology 40:1060-1076.

Kinley, T. A., and N. J. Newhouse. 1997. Relationship of riparian reserve zone width to bird density and diversity in southeastern British Columbia. Northwest Science 71: $75-86$.

Kirkman, L. K., M. B. Drew, L. T. West, and E. R. Blood. 1998. Ecotone characterization between upland longleaf pine/wiregrass stands and seasonally-ponded isolated wetlands. Wetlands 18:346-364.

Kis-Papo, T., I. Grishkan, A. Oren, S. P. Wasser, and E. Nevo. 2001. Spatiotemporal diversity of filamentous fungi in the hypersaline Dead Sea. Mycological Research 105:749756.

Krueper, D., J. Bart, and T. D. Rich. 2003. Response of vegetation and breeding birds to the removal of cattle on the San Pedro River, Arizona (USA). Conservation Biology 17:607-615.

McComb, W. C., C. L. Chambers, and M. Newton. 1993. Small mammal and amphibian communities and habitat associations in red alder stands, Central Oregon Coast Range. Northwest Science 67:181-188.

McGarigal, K., and W. C. McComb. 1992. Streamside versus upslope breeding bird communities in the Central Oregon Coast Range. Journal of Wildlife Management 56:10-23.

McIntyre, N. E. 2000. Community structure of Eleodes beetles (Coleoptera: Tenebrionidae) in the shortgrass steppe: scale-dependent uses of heterogeneity. Western North American Naturalist 60:1-15.

Naiman, R. J., R. E. Bilby, and P. A. Bisson. 2000. Riparian ecology and management in the Pacific Coastal Rain Forest. BioScience 50:996-1011.

Naiman, R. J., and H. Decamps. 1997. The ecology of interfaces: riparian zones. Annual Review of Ecology and Systematics 28:621-658.

Naiman, R. J., H. Decamps, and M. Pollock. 1993. The role of riparian corridors in maintaining regional biodiversity. Ecological Applications 3:209-212.

Nevo, E. 1995. Asian, African and European Biota meet at Evolution Canyon, Israel: local tests of global biodiversity and genetic diversity patterns. Proceedings of the Royal Society of London, Series B-Biological Sciences 262:149155 .

Nevo, E., O. Fragman, A. Dafni, and A. Beiles. 1999. Biodiversity and interslope divergence of vascular plants caused by microclimatic differences at "Evolution Canyon," Lower Nahal Oren, Mount Carmel, Israel. Israel Journal of Plant Sciences 47:49-59.

Nevo, E., S. Raz, and A. Beiles. 1996. Biodiversity of reptiles at "Evolution Canyon," Lower Nahal Oren, Mount Carmel, Israel. Israel Journal of Zoology 42:395-402.

NRC (National Research Council). 2002. Riparian areas: functions and strategies for management. National Academy Press, Washington, D.C., USA.

Pavlicek, T., C. Csuzdi, G. Smooha, A. Beiles, and E. Nevo. 1996. Biodiversity and microhabitat distribution of earthworms at "Evolution Canyon," a Mediterranean microsite, Mount Carmel, Israel. Israel Journal of Zoology 42:449-454.

Pearson, S. F., and D. A. Manuwal. 2001. Breeding bird response to riparian buffer width in managed Pacific Northwest Douglas-fir forests. Ecological Applications 11:840-853.

PlantyTabacchi, A. M., E. Tabacchi, R. J. Naiman, C. Deferrari, and H. Decamps. 1996. Invasibility of species rich communities in riparian zones. Conservation Biology 10: 598-607. 
Pollock, M. M., R. J. Naiman, and T. A. Hanley. 1998. Plant species richness in riparian wetlands: a test of biodiversity theory. Ecology 79:94-105.

Schade, J. D., R. Sponseller, S. L. Collins, and A. Stiles. 2003. The influence of Prosopis canopies on understorey vegetation: effects of landscape position. Journal of Vegetation Science 14:743-750.

Skagen, S. K., C. P. Melcher, W. H. Howe, and F. L. Knopf. 1998. Comparative use of riparian corridors and oases by migrating birds in southeast Arizona. Conservation Biology 12:896-909.

Treonis, A. M., D. H. Wall, and R. A. Virginia. 1999. Invertebrate biodiversity in Antarctic dry valley soils and sediments. Ecosystems 2:482-492.
Trewartha, G. T. 1937. An introduction to weather and climate. McGraw-Hill, New York, New York, USA.

Wasser, S. P., E. Nevo, O. N. Vinogradova, I. L. Navrotskaya, I. A. Ellanskaya, P. A. Volz, V. M. Virchenko, P. M. Tsarenko, and S. Y. Kondratyuk. 1995. Diversity of cryptogamic plants and fungi in "Evolution Canyon," Nahal Oren, Mount Carmel Natural Preserve, Israel. Israel Journal of Plant Sciences 43:367-383.

Woinarski, J. C. Z., C. Brock, M. Armstrong, C. Hempel, D. Cheal, and K. Brennan. 2000. Bird distribution in riparian vegetation in the extensive natural landscape of Australia's tropical savanna: a broad-scale survey and analysis of a distributional data base. Journal of Biogeography 27:843868 .

\section{APPENDIX A}

A table showing a summary of site characteristics, taxa studied, and methods used in sampling the taxa is available in ESA's Electronic Data Archive: Ecological Archives E086-003-A1.

\section{APPENDIX B}

A table showing a comparison of results assuming $95 \%$ and $99 \%$ confidence intervals (CI) is available in ESA's Electronic Data Archive: Ecological Archives E086-003-A2. 